\title{
THE INFORMATION AS THE ESSENTIAL ELEMENT IN COMMUNICATION MANAGEMENT
}

\author{
KurtuhuZ, A. M.; RADU, D. L.; ANGHel, A.; ZAhiU, C.; \\ SAlisteanu, I. C., UdroiU, I. N. \& DUMitricA, M. A.
}

Abstract: The proper functioning of the organization and the objectives included in its forecast, there are only possible through the contribution of decision - his nervous system. It is necessary an information system that can be compared with the circulatory system in the human body, providing the raw material and information necessary to establish management objectives, tasks, powers and responsibilities of both management and execution of the organization. The information is the essential support in decision making and communication management.

Key words: management, information, decision making, communication
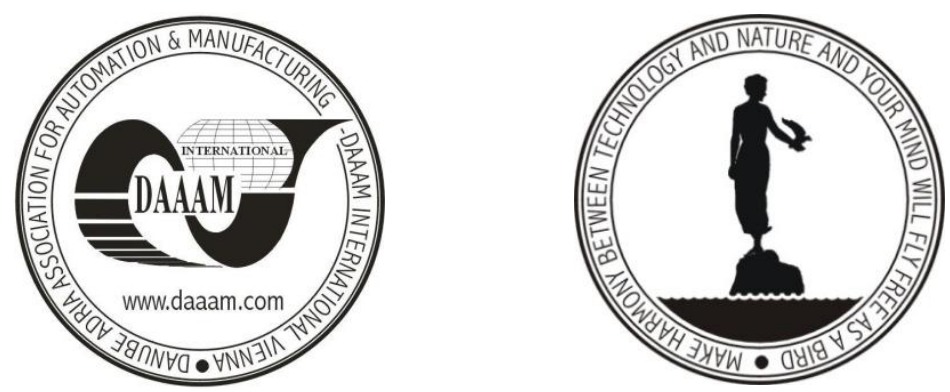

Authors' data: As.Univ.Dr.Ec. Kurtuhuz, A[ndreea] M[aria]; As.Univ.Drd. Radu, D[aniela] L[iana]; Lect.Univ.Dr. Anghel, A[lina]; S.l.Univ.Dr.Ing. Salisteanu, I[oan] C[orneliu]; S.l.Univ.Drd.Ing. Udroiu, I[ulian] N[icolae]; As.Univ.Drd. Zahiu, C[amelia] E[lena] \& As.Univ.Drd. Dumitrica, M[ihaela] A[ndreia]; University of Valahia, Bd.Carol I, No.2, 130024, Targoviste, Dambovita, Romania; andreea.kurtuhuz@yahoo.com, rvalahia@yahoo.com

This Publication has to be referred as: Kurtuhuz, A[ndreea] M[aria]; Radu, D[aniela] L[iana]; Anghel, A[lina]; Zahiu, C[amelia] E[lena]; Salisteanu, I[oan] C[orneliu]; Udroiu, I[ulian] N[icolae] \& Dumitrica, M[ihaela] A[ndreia] (2013) The Information as the Essential Element in Communication Management, Chapter 34 in DAAAM International Scientific Book 2013, pp. 619-628, B. Katalinic \& Z. Tekic (Eds.), Published by DAAAM International, ISBN 978-3-901509-94-0, ISSN 17269687, Vienna, Austria

DOI: $10.2507 /$ daaam.scibook.2013.34 


\section{Introduction}

The importance of information and information systems was synthesized by $\mathrm{J}$. Naisbitt as the result of a calculation to try to determine how many percent of the U.S. workforce is directly involved in the creation, use or distribution of information. Given that the study was conducted in the early 80's results are impressive, even for the United States - the percentage of so-called knowledge workers proved to be around $70 \%$ of the total. The development of information technology has led to the inclusion of information that sixth organizational resource, along with human resources, machinery, financial resources, materials and management.

This study proposes a trip circuits, information flows and procedures, decision support systems with the deepening of expert systems for decision support. In expert systems, intelligent processing uses the fundamental knowledge representing logical and semantic correlations between facts through reasoning rules.

\section{Information as the Essential Element in Decision Making in Communication Management}

Even with intangibility, the information is a highly efficient and economical way to meet other resources of the company. In addition, the information is used both to assist in coordinating activities of the other five organizational resources, and for planning, directing and controlling these activities. In this context, building systems responsible for assisting decision appears as a priority for the new wave of managers. In a ranking of the importance of resources in terms of management, second only to the human factor is the quality and frequency of information business (Harrington, H.J.\& Harrington, J.S. 1995).

Dynamic process management side is the quantity and quality of existing information assembled logical information system. Based on a continuous flow of information upward and downward can track and adjust the whole activity of administrative and economic unit.

Information system can be defined as the set of data, information, circuits, and information flows, procedures and means of handling information meant to help set and achieve unity (Nicolescu, O. \& Verboncu, I, 2008).

Information System provides permanent knowledge of economic processes and has a growing impact on the development and greater administrative efficiency units. Through it provides information to substantiate its decision, it shall provide the necessary knowledge achievement of objectives at certain predetermined periods etc. Between information system and computer system there are differences, although the utility management activities have the same role. The computer systems has similar objectives and fulfill the same functions, but informational processes used to conduct the procedures provided by management science, systems theory, economic cybernetics, operational research etc. played by automatic means.

The computer system is considered a group of computer equipment, procedures combined, organized to process data in order to achieve certain measurable performance criteria established. 
It follows from the foregoing that, simply replacing traditional means of calculation, or when only part of the information is processed in this way does not lead to a system, but we have a computer system with automatic data processing means.

Information system has the following components: data, information, a carrier of information flow and information flow, information and means of treatment procedure information.

Data can be defined as: concept, fact, event, process, object or action from inside or outside the system, represented in a suitable conventional form of communication, interpretation or processing them. In the information process the data represents the depiction of figures or information on Letra processes, resources, etc. and it can be used in the management activity as such (information) or subjected to manufacturing processes to increase its significance and usefulness. Information system is to collect data on operational subsystem, to process them and transmit information in the form of functional subsystem that uses the knowledge and control of the business unit.

Information is the main component of the information system is defined as a notice, communication, message about the condition or conditions of economic processes and phenomena, scientific, social, technical, cultural and so on, which is a novelty and interest to the recipient, increasing so its awareness on the results. Information can be defined as a new message with the character of the events that took place, place, or will take place both inside the system and outside it, and of interest to the receiver.

In order to convey ideas and those who understand them to be transmitted, the manager use symbols you know, plus various codes, graphics, etc electronic pulses. Information must be a factual basis for the development decisions in the organization.

A carrier constitutes material information that is entered circulation of information and serving and storing them. Range of information carriers is divided into two categories: classic carriers (primary documents, technical documents operative records, etc.) And modern carriers (magnetic tape, magnetic disk) etc. The use of one or other of the information carriers depending on the degree of public administration unit equipped with means of handling information and knowledge of staff working with them.

The information flow is all the information communicated in a period of time from the information source to the receiver via channel system information. An information system contains several information flows, and a lot of connections that are established between various components thereof. Administrative unit level information flows are grouped in relation to its functions.

The route of the flow information is information at their collection to the place of use or storage thereof. The itinerary involves the timing of all operations of data until the appearance of an action or destruction of information. Information flow length is determined by a number of factors, including the most important are: purpose vehicle information, position in the organizational structure of the Centre transmitters and receivers, data processing speed, capacity communication channels, 
etc. The channel length is less flow of information the information flow will be operative. The work to improve the information system of an administrative unit, streamlining

circuit

Information is at the forefront.

Information procedure is a sequence of operators with a certain degree of generalization routine nature, which provides performance data to solve a problem using the specific means and methods. The computer program is a sequence of instructions procedure forming a logical entity without being necessarily an independent unit of the program.

Procedures consist of a number of factors which determine how the collection, integration, transmission, processing and presenting information. Role procedures are to establish an information support use of the means used for the collection, recording, transmission, processing and presentation of information handling sequence information and operations that they support, and computational methods used, etc.

The quality of procedures is determined by the degree of satisfaction of managers and contractors with the necessary information. Content information procedures should ensure the development of decision-making and create the optimum conditions for each manager of office management.

Means of treating information as a basic component of the information system are represented by all equipment which performs operations on a set of data and to obtain information necessary for the management of the administrative units. Functional quality of management information system is subject to the means of collection, processing, transmission and disclosure.

Data processing involves achieving the following actions: establish goals data processing, systematization of facts collected, detection and causes that generate content material weaknesses, the theoretical conclusions and their generalization, analysis of information obtained from data processing.

After collection activities and data processing, the information obtained should be submitted as soon as possible beneficiaries to be used for the purpose of the opening action.

To ensure an effective management information system functioning in administrative units must comply with the following principles:

a) providing a minimum amount of initial data that accurately reflects economic and social phenomena and the process can generate a maximum of derivative information, presented in an easily accessible form, avoiding concentrations of primary data to ensure obtaining a complete system parameters or indicators or derivatives;

b) providing accurate information flow in sufficient volume to each manager regardless of the hierarchical level at which it is located;

c) providing timely information in order to ensure a sufficient time interval between the sending and the materialization of their initial share; d ) sequences of existing information on the route information flows should enable 
the event the cooperation between the different components of the organizational structure ;

e) ensuring the superior information through their use in calculations of economic efficiency and economic analysis.

Information, the message it carries, can trigger reactions, which in turn determines the action. The force shall respond to information in terms of analysis and initiation of measures, the factors can easily remove the negative impact on the system. This calls for a communication between the operational and functional subsystem, early action, during and at the conclusion.

After establishing the misconduct, it is formed the intermediate data by recurrent, the first utility for decision making and initiate corrective action to determine the functionality of the system to default settings.

Optimal operation of the system - organization - requires the existence of internal information and external connections caused by information flow upward and downward from the global system to which it belongs. Economic information is present wherever it is directing an action, ensuring knowledge of economic phenomena and processes, thereby reducing the risk and uncertainty.

The information is a permanent manager, both in the development and implementation of decisions and throughout their fulfillment through the pursuit of performance to be achieved in the interim deadlines for each component of the process execution ( Kurtuhuz, A.M. et.al., 2011).

It analyzes the information received on the achievement of the various decisionmaking stages and resume if necessary correction decisions. The efficiency of management is influenced by the quality of information and the efficiency of collection, processing, transmission and conversion into mounts decisions. Information circulating in a unit may be systematized and grouped according to several criteria. Their goal is to a systematic ordering and facility the work of collecting, processing and providing managers are on different levels, for use in decision making.

The first criterion is the classification of the information management system elements.

According to this criterion, the information may include: management, such as decisions made by managers, and reporting subsystem provided operational on specific tasks in predetermined steps.

A second criterion for the classification of information is the functional characteristics, they can be: the status, input, output, cooperation and execution. Status information characterizes quantitative and qualitative technical production potential of the unit and its constituent subdivisions. In this group are included the information concerning: the areas of land use categories and crops, livestock production, stocks of materials and products, amounts held in account, the main economic indicators, etc. 
Input information characterizing quantitative and qualitative inputs, both at the system and subsystem components, refer to the quantities of inputs to be purchased and distributed to farms and consuming sectors, the services to be performed by third parties, etc.

Output information characterizing the influence exercised by the administrative unit on the environment and includes: products and services delivered; communications to organizations coordinating government units, etc.

Information expresses links organizational cooperation that are established both within the unit and between the unit and other businesses. Performance information reflects the conduct of current business and operational management of the administrative unit.

After landing, the information is divided into: information programming, preparation, launch, control, control, evaluation and reporting.

Programming information are those that provide support decision making and strategy development plans for certain periods of time, both at the unit level and the organizational subdivisions.

Information release preparation is used for decision making regarding the preparation and launch their work in logical sequence.

Information control and adjustment are the resulting from operational monitoring of the activities of the administrative unit managers by exercising control. This group of information of particular interest because their place on deciding on corrective decisions. This information is used to initiate actions to stop the negative influence of random factors and restore the functionality of the default settings. After the period covered by the data can be grouped into: information assets, liabilities and forecasting.

Active or dynamic information, it is circulating during the economic processes and enable managers to ensure effective intervention system operation. Improving information handling means are measures to ensure a high degree of efficiency on current decisions.

Passive information reflects economic processes occurred. They are used for comparative analyzes, calculations, etc. trends.

Information forecasting reflects the trends in a subsequent period of economic phenomena and processes.After the expression, information can be grouped into: written, oral and audio -visual Information. In different areas, there are other criteria of classification of the information, but the above can be found with a frequency in the activity practice management in economic units.

Knowing the types of information that are conveyed in an economic matter, because each type of information has certain characteristics that must be considered to ensure optimal functionality of the entire system and its components.

In the process of decision making and adoption of effective, economic and social decision, the information plays a decisive role. To do this, they must meet certain requirements, including consideration: accuracy, timeliness, quantity, appropriate content, frequency, information age etc.

Accuracy, determine the value of information and concerns accurate reflection of reality, both quantitatively and qualitatively. She plays the correspondence 
between the quantitative size of the phenomenon or process represented on existing information and real economic system.

Accuracy of information can be determined in two ways (Duica, A. 2008):

1) The exact value of the ratio between the number of responses and the total number of answers to the question about economic processes pursued. The value of this ratio is close to unit, the information was accurate, the ideal situation is when the ratio is equal to unity;

2) By the coefficient of accuracy.

Knowing the accuracy of the information is of great practical importance because the total amount of information obtained is useful only part of the aim pursued, namely the corresponding coefficient accurately (Hesselbein, F., et.al. 1995). The value of this coefficient is higher; it will provide a higher level of certainty decisions.

Between the accuracy of the information and the decision-making process that is sized, there must be a relationship compatibility, otherwise, it creates a situation exactly sub information or excessive.

Sub information leads to decisions without scientific support and an increasing uncertainty.

Excessive accuracy, leading to higher costs of information than necessary, negatively influencing the decision making process deployment costs. The insurance business decision making with the volume and quality of information required for each type of decision, a special role of methods and techniques used in the collection and treatment of data.

Opportunity is the quality of information being available at the time required by the decision maker. This requires the establishment of measures to ensure shortening cycle: production - processing - transmission - reception - use of information to minimize the process of ,aging ,them.

Opportunity is the linkage that exists between the nature of the phenomenon or economic process information and the reality reflected by its size. The dynamic evolution of the phenomena and processes of information content requires comparing real phenomenon that it is, when its collection. After completing a certain period evolving economic phenomena and processes, and information previously gathered lose their significance, their use in decision making will increase the deviations from the expected consequences decider.

This requires that the decision-making process, regardless of the decision to be taken, information should be authentic.

The amount of information that enters a system, per unit time, shall satisfy the needs for which they were requested, without producing the phenomenon of overinformation.

The phenomenon of over-information can be particularly at managers who have a clear vision and system factors that negatively influence the directions of action for removal. The extra time are wasted over-information collection, processing and transmitting that information to which the manager does not need unduly increasing the driving expenses. 
Kurtuhuz, A. M.; Radu, D. L.; Anghel, A.; Zahiu, C.; Salisteanu, I. C.; Udroiu,...

Sub information, great harm decision making because decisions are taken without proper scientific foundation and the real consequences will deviate much from those initially evaluated them decider.

Appropriate content aims to ensure full correspondence between the content and nature of decision problems to be solved.

The frequency of the information is up with the ongoing need for information centers and the need for decision making. To be able to fulfill their role, information must be collected, processed, stored and transmitted, moments that are known as the flow of information and are designed as a "system" forming a unified whole.

The information management process must be continuous, fast and ensure the connection is reversed. This means that the information provided to managers are those arising from previous decisions, complete with related content.

A rational circulation of information it requires low-cost realization, which can accomplish by avoiding duplication or sending them repeated the same channel. Information age is the time elapsed between the time of registration and the information they use in decision making. At present we are witnessing a rapid obsolescence of information especially those with scientific, determined by the progress being made in this area.

The management practice of organizations should reduce as much as possible the time of the registration and use of information in order to get to a reduction of an uncertainty sphere and the real consequences of the decisions they approach evolved decider.

In an ideal situation, managers should be able to define the type of information they need, and management information system should be capable of receiving an offer. In practice, however, this is not always possible.

As Peter Drucker believes, " Most decisions should be based on incomplete knowledge or because the information is not available, either because it would cost too much time and money to get it."(Druker, P. 1954). However, to make the right decision, managers must have the relevant information that increase knowledge, reduce uncertainty, and are useful for the purpose.

Extremely important for managers is also the value of information, the value derived from changes in decision behavior caused by the availability of information. In appreciation of information should be taken into consideration but the cost of producing them. The acquisition, handling, recording and processing of data, by whatever means, do not produce value but involving only cost. Value only appears when data are communicated and understood by the recipient transforming into information. In evaluating the information in terms of the value created, it has a crucial role its users and the manner in which information is used to improve decision making.

Good information is the information that creates value through use and is characterized by the following elements: it is relevant to the purpose, is sufficiently accurate for its purpose, is quite complete for the problem referred to is from a trusted source that the user is notified in time for the purpose or is appropriately detailed, is communicated through a proper channel and is understood by the user. Another major problem facing managers is the sheer volume of information. A large amount of information can not only cause bottlenecks and congestion of the system but may prevent managers in their tasks. Previous computer systems containing a large 
number of data, but they were transformed into information only when they were involved in decision support.

Unfortunately, data are often confused with information and this leads to situations where managers are forced to make important decisions in the absence of relevant information. Planning and good control of operations through effective decisions should be based on a constant flow of quality information and in real time. The data must be processed and sent to the appropriate recipient in a short enough time to change or control the entire operational environment.In these circumstances and given the accelerated pace of business, the need to use a defined system to assist managers. The system should not impede the rational managers, but must increase their capacity and become an extension of reason managers.Computer technology and data communication change the parameters in which the competition in all fields. If in the past it was information technology oriented data storage in the modern world it should provide a dynamic vision of the organization, facilitating adaptation to changing business environment and ensuring its competitiveness (Kurtuhuz, A.M. et al, 2009). In this way, information technology is a highly effective weapon in the competition objectives of the organization. In addition, it is applicable in any field and any size organization.

You cannot get real competitive advantage without increasing worker productivity when assisting management systems, workers are represented by managers. Until recently, all discussions relating to management productivity ignored the problem; they are focusing on productivity workers at lower levels of an organization. Seen from a strictly financial perspective, labor productivity and workers is, however, only part of the organization's productivity. For example, if management decides to launch a new product that customers will not buy it, it is irrelevant whether the workers who made the product work effectively or not (Stegaroiu, I. et.al.,2005). A good product at the right time will have a greater impact on the organization than the workers labor productivity improvement. One of the reasons for not attaches particular importance to the present productivity and management is that the manager, the decisions you take, do not provide stand-alone product. Thus, it is difficult to measure by conventional methods productivity (quantity of products manufactured / time, etc.). Productivity management should be measured by the quality of decision making and time to them. They depend largely on the quality and frequency of information, issues that have been discussed above.

\section{Conclusion}

Currently, even if the information is not undervalued, underestimated and underused as in previous years, there are still a number of issues related to its use in decision-making.

In conclusion, the results of the research illustrated that information can be used by an organization as a sixth resource; it must meet the following conditions:

- To respond as quickly to changing competitive conditions, in this way can be exploited quickly new opportunities and competitive vulnerable points may be reduced; 
- To increase internal efficiency and productivity of the organization emphasizing productivity manager, this requires better coordination of functional elements of the organization;

- To improve creativity, productivity and effectiveness of individual and group decision makers within the organization, this means providing appropriate tools to collect information and real time analysis of data and quality improvement decisions and sending, support and monitor the implementation of actions and decisions management.

These three conditions are required from the information to get the certainty that will provide competitive advantages for the organization and improve productivity management. Recent studies suggest that, in general, these problems relate to the quality and value of information, the amount of information transmitted to managers and their periodicity.Practice management of administrative and economic organizations (Petrescu, $\mathrm{M}$ et al, 2010) highlighted the direct link that exists between the management process itself and the existing information system.

These days, the competition has become a current problem and difficult for any organization. This raises the need for organizations to obtain competitive advantages. One way is to use appropriate information technology, it is the task for top management systems.

\section{References}

Drucker, P. ( 1954). The Practice of Management, Harper \& Row, New York

Duica, A. (2008). Management, Editura Bibliotheca, ISBN 978-973-712-436-4, Targoviste

Harrington, H.J.\& Harrington, J.S. (1995). Total Improvement Management: The Next Generation in Performance Improvement, New York: McGraw-Hill

Hesselbein, F. et.al. (2000). Organizația viitorului, Editura Teora, ISBN 973-601947-0, București

Kurtuhuz, A.; Vasilescu, I.; Badea, R. \& Popescu, A. (2009). Reform in the Year of Economic Crisis, Annals of DAAAM for 2009 \& Proceedings of the 20th International DAAAM Symposium, 25-28th November 2009, Vienna, Austria, ISSN 1726-9679, ISBN 978-3-901509-70-4, Katalinic, B. (Ed.), pp. 1919-1920, Published by DAAAM International Vienna, Vienna

Kurtuhuz, A. M.; Vasilescu, I.; Lupu, F.; Lupu, A. G.; Radu, D. L.; Kurtuhuz, M. C. (2011). The manager role in decision making, Annals of DAAAM \& Proceedings of the 22nd International DAAAM Symposium, Volume 22, No. 1, ISSN 1726-9679 ISBN 978-3-901509-83-4, Editor B. Katalinic, Published by DAAAM International, Vienna, Austria, EU, 2011

Nicolescu, O. \& Verboncu, I. (2008). Fundamentele managementului organizatiei, Editura Universitara, ISBN 978-973-749-448-1, Bucuresti

Petrescu M., Stegaroiu I., Braboveanu Mi., Petrescu A. G., Sîrbu N., Implementing a risk management approach for optimizing, information security systems, Business Transformation through Innovation and Knowledge Management: An Academic Perspective, Proceedings of The 14th International Business Information Management Association Conference, June 23 - 24, 2010, Istanbul, ISBN: 978-09821489-3-8, Turkey 